\title{
Effect of GGBS and Nano Silica on the Durability Properties of Ternary Concrete
}

\author{
Kaushal Vora1 ${ }^{1}$, Niragi Dave ${ }^{2}$, Manank Shah ${ }^{1}$, Dhruv Shah ${ }^{1}$ \\ ${ }^{1}$ School of Technology, Pandit Deendayal Petroleum \\ University Gandhinagar, Gujarat- 382007, India \\ vorakaushal20@gmail.com; manank.scv15@sot.pdpu.ac.in; dhruv.scv15@sot.pdpu.ac.in \\ ${ }^{2}$ Assistant Professor, School of Technology, Pandit Deendayal Petroleum University \\ Gandhinagar, Gujarat- 382007, India \\ niragi.dave@sot.pdpu.ac.in
}

\begin{abstract}
The cement industry is the most energy consuming and $\mathrm{CO} 2$ producing industry. Many efforts has been taken to reducing the cement content in construction industry using supplementary cementitious materials(SCM). Aim of this research work is using supplementary cementitious materials(SCMs),such as Ground Granulated Blast furnace Slag(GGBS) and Nano-Silica(Average particle size- $15 \mathrm{~nm})$ combinations with Ordinary Portland Cement(OPC).The Nano-Sillica is partially replace with cement at dosages of $1 \%, 2 \%, 3 \%, 4 \%, 5 \%$ and also $50 \%$ Ground Granulated Blast furnace Slag(GGBS) to find effect of durability properties of High streng th concrete(HSC). Replace with cement content for significant improvements in performance were we observed that Nano-Silica gives better durability compare to $100 \%$ Ordinary Portland Cement(OPC) controlled concrete. Durability assessments such as rapid chloride permeability test(RCPT)(at ages of 28,56 and 90, 180 days), Sorptivity test( at age of 90 days), sulfate attack test( at age of 56,90 and 180 days), Ultrasonic pulse velocity(UPV)test(at age of 28, 56, 90 and 180 days) and Acid attack test( at age of 90 days) is revealed significant resistance against chloride penetration, water absorption, sulfate chemical also check. These improvements can mainly due to larger specific area of Nano-Silica, which effectively stimulates both pozzolanic reactivity and filler effect over the cementitious matrix. Due to its specific properties ,Nano-silica may constitute the significant improvement of the quality of the concrete structure. Application of nanotechnology is an effective way to reduce environment pollution and improve durability of concrete. Nano silica replace with cement at dosages of $4 \%$ gives the optimum results of the durability properties of concrete.
\end{abstract}

Keywords: Nano Silica, Ground Granulated Blast furnace Slag(GGBS),Durability, Sorptivity Test, Sulfate Attack Test, Ultrasonic pulse velocity(UPV), RCPT, Acid attack test.

\section{Introduction}

During recent years, Nano Technology is developing with faster rate, especially in construction materials like cement paste and concrete. Many of the studies are available on the effect of Nano particles on properties of harden cement paste and concrete, also the use of the SCMs has always resulted many advantages like increases in durability of concrete and reducing impact on the environment by reducing green house effect. Nano particles as Nano silica are produce from silica sand. Some research on concrete are done for improving workability and strength of the concrete or mortar mix. Researchers are used Micro materials like silica flume for improving strength and durability of the concrete as a research projects, but few years ago researchers found out that Nano silica are more efficient in strength and durability point of view for the concrete mix.

Concrete is the most widely used construction material because of its many applications. In the concrete cement is major constituent of the concrete industry and is considered to be the most energy consuming has high rate of CO2 emissions. The cement industry produces about 5\% to $10 \%$ of global man made CO2 emissions in one year. Something about 0.9 tone of $\mathrm{CO} 2$ are emitted for every 1 tone of cement productions. During past years many research are going on replacement of cement with different SCMs materials.

The use of SCMs materials, such as, fly ash, ground granulated blast furnace slag and other pozzolana are improves the resistance of concrete against acid attack, chloride ions. GGBS- Ground granulated blast furnace slag is by product from the blast furnaces used to make iron. This is the most widely use SCMs with replacement of cement in concrete mixes. The use of supplementary cementitious materials as partial replacement to Portland cement in concrete is a better step towards sustainable development because of their technological, economic, and environmental benefits. Some research shows that using GGBS in concrete mix increases durability and reducing permeability. 
The main study of the objective to achieve information about effect of SCMs on concrete mixes. In this study using nano silica, ground granulated blast furnace slag as partial replacement with Ordinary Portland cement (OPC) on the durability of concretes and based on the results to propose an optimum concrete mixes and using OPC with SCMs and Nano Slica we improved durability properties of concrete.

\section{Materials and Methods}

Materials used in this research work are: OPC (53 grade) conforming to IS: 12269:1987 and Ground Granulated Blast furnace Slag (GGBS) whose chemical and mineralogical properties are shown in Table 1. Nano Silica (Hydrophilic Nano powder, Reinste Nano Ventures) has been substituted 1\%, 2\%, 3\%, 4\% and 5\% by weight whose chemical constituents are shown in Table 2. In the present study, Super Plasticizer (SP) of Carboxylic Ether (CONFLOW SNS 2, Essence Construction) with specific gravity 1.21 was used. It was used to decrease the water demand while improving the workability of all the concrete mixes. The Super plasticizer dosage was adjusted for each mix to ensure that no segregation would occur.

The gravel used was crushed gravel with size less than $12.5 \mathrm{~mm}$ in accordance to ASTM standard grading curve. The fine aggregate used was river sand conforming to IS: 383 and passing from sieve size of $4.75 \mathrm{~mm}$. The physical properties of river sand are presented in Table 3.

We are prepared test for finding durability properties of concrete and were we perform test like Sorptivity test, UPV(Ultrasonic pulse velocity), Acid test, Sulfate attack test, RCPT( Rapid chloride permeability test) and Sulfate attack test. We casted the concrete specimens for each batch, that comprising Size of 100mm dia. And 50mm height for RCPT( 28,56, 90 and 180 days) test and 50mm x 50mm x 50mm for the sulfate attack test (28,56 and 90 days).

Table 1: Chemical and mineralogical properties of OPC, GGBS, and NS.

\begin{tabular}{|c|c|c|c|c|}
\hline & Water & $\mathrm{OPC}$ & GGBS & Nano Silica \\
\hline \multicolumn{5}{|c|}{ Physical Characteristics } \\
\hline Specific Gravity & 1 & 3.15 & 3.14 & $2.4-2.6$ \\
\hline Blaine's Fineness, $\mathrm{cm}^{2} / \mathrm{gm}$ & - & 2285 & 3250 & $10,00,000$ \\
\hline \multicolumn{5}{|c|}{ Chemical Characteristics } \\
\hline Calcium oxide, Cao, $\%$ & - & 66.73 & 35.9 & - \\
\hline Silicon dioxide, $\mathrm{SiO} 2, \%$ & - & 17.54 & 40.65 & 99.9 \\
\hline Aluminum oxide, $\mathrm{Al} 2 \mathrm{O} 3, \%$ & - & 9.82 & 17.07 & - \\
\hline Ferric oxide, $\mathrm{Fe} 2 \mathrm{O} 3, \%$ & - & 2.19 & 0.68 & - \\
\hline Manganese oxide, $\mathrm{MnO}, \%$ & - & 0.02 & 0.03 & - \\
\hline Magnesium oxide, $\mathrm{MgO}, \%$ & - & 1.24 & 3.75 & - \\
\hline Potassium oxide, $\mathrm{K} 2 \mathrm{O}, \%$ & - & 0.48 & 0.56 & - \\
\hline Sodium oxide, $\mathrm{Na} 2 \mathrm{O}, \%$ & - & 0.22 & 0.19 & - \\
\hline Loss of ignition, $\%$ & - & 0.9 & 0.08 & - \\
\hline
\end{tabular}


Table 2: The mix design concrete samples used in study.

\begin{tabular}{|c|c|c|c|c|c|c|c|c|}
\hline & & \multicolumn{7}{|c|}{$\mathrm{Kg} / \mathrm{m}^{3}$} \\
\hline $\begin{array}{c}\text { Mix } \\
\text { No. }\end{array}$ & Mix & Cement & GGBS & $\begin{array}{c}\text { Nano } \\
\text { Silica }\end{array}$ & $\begin{array}{c}\text { Coarse } \\
\text { Aggregate }\end{array}$ & $\begin{array}{c}\text { Fine } \\
\text { Aggregate }\end{array}$ & Water & SP \\
\hline 1 & $100 \%$ OPC & 594 & 0 & 0 & 755.5 & 807.5 & 208 & 8.07 \\
\hline 2 & $50 \%$ OPC+50\% GGBS & 297 & 297 & 0 & 755.5 & 807.5 & 208 & 8.07 \\
\hline 3 & $49 \%$ OPC+50\% GGBS+1\% NS & 291.06 & 297 & 5.94 & 755.5 & 807.5 & 208 & 8.07 \\
\hline 4 & $48 \%$ OPC+50\% GGBS+2\% NS & 285.12 & 297 & 11.88 & 755.5 & 807.5 & 208 & 8.07 \\
\hline 5 & $47 \%$ OPC+50\% GGBS+3\% NS & 279.18 & 297 & 17.82 & 755.5 & 807.5 & 208 & 8.57 \\
\hline 6 & $46 \%$ OPC+50\% GGBS+4\% NS & 273.24 & 297 & 23.76 & 755.5 & 807.5 & 208 & 8.57 \\
\hline 7 & $45 \%$ OPC+50\% GGBS+5\% NS & 267.3 & 297 & 29.7 & 755.5 & 807.5 & 208 & 8.98 \\
\hline
\end{tabular}

\section{Results and Discussion}

\subsection{Rapid Chloride Permeability Test (RCPT)}

Standardized test procedures are ASTM C 1202. The RCPT is performed to find out the amount of current passing through a sample $100 \mathrm{~mm}$ diameter and $50 \mathrm{~mm}$ thick in 6 hours. In fig. 1 shows RCPT test cubes. A reduction in charge is indicate the better resistance against the chloride ions. SCMs replace with cement caused reduction in chloride penetration in concrete. Low chloride permeability with high volume of SCMs will make structure dense. Due to pozzolanic reaction may cause reduction in capillary pores which reduces chloride penetrations in concrete. From this study, it was observed that ternary concrete gives the better results than binary and 100\% OPC controlled concrete. In these study mix 6 and Mix 7 gives the optimum results. Table shows the RCPT values have decreased with testing age. From the results we conclude that low water/cement ratio and pozzolans affects the RCPT values.

Table 3: Test Results of RCPT for difference mixes.

\begin{tabular}{|c|c|c|c|c|c|}
\hline \multirow{2}{*}{ Mix } & Mix & \multicolumn{5}{|c|}{ Rapid Chloride Permeability Value(Coulombs) } \\
\cline { 3 - 6 } & no & 28 Days & 56 Days & 90 Days & 180 Days \\
\hline $100 \%$ OPC & 1 & 3120 & 2845 & 2120 & 1560 \\
\hline $50 \%$ OPC+50\% GGBS & 2 & 1200 & 1026 & 898 & 743 \\
\hline $49 \%$ OPC+50\% GGBS+1\% NS & 3 & 621 & 502 & 429 & 392 \\
\hline $48 \%$ OPC+50\% GGBS+2\% NS & 4 & 532 & 424 & 252 & 167 \\
\hline $47 \%$ OPC+50\% GGBS+3\% NS & 5 & 469 & 219 & 128 & 102 \\
\hline $46 \%$ OPC+50\% GGBS+4\% NS & 6 & 322 & 102 & 78 & 61 \\
\hline $45 \%$ OPC+50\% GGBS+5\% NS & 7 & 410 & 287 & 137 & 59 \\
\hline
\end{tabular}

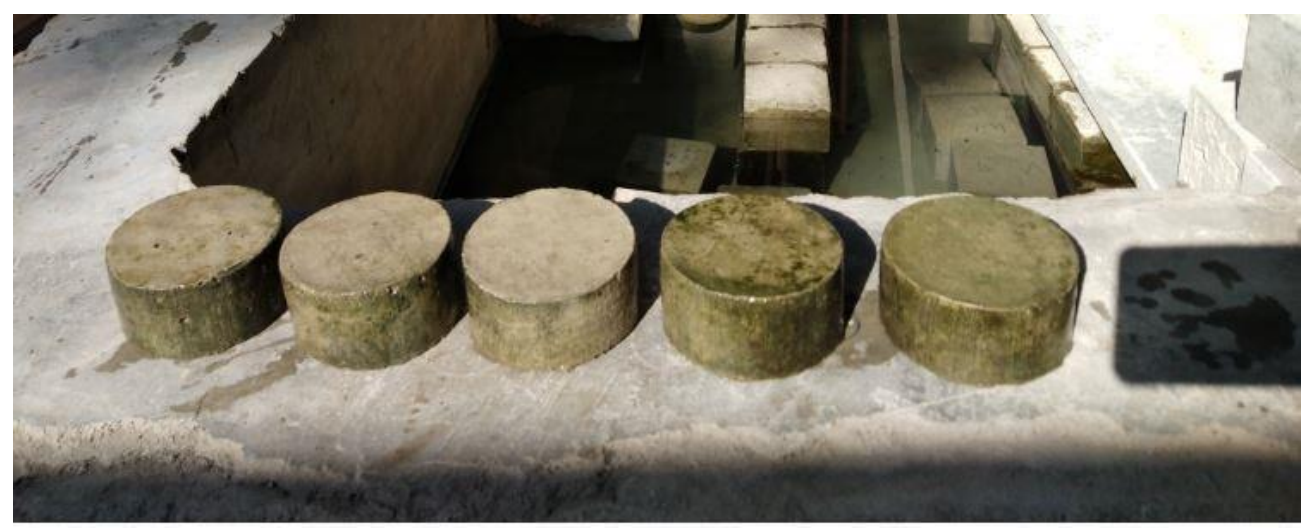

Fig. 1: RCPT test cubes. 


\subsection{Sorptivity Test}

This Test is measures the rate of penetration of water into the concrete cube by capillarity suction. In this test specimen size is $100 \mathrm{~mm}$ diameter and $50 \mathrm{~mm}$ thick. In fig. 2 shows the cubes of sorptivity test. After casting the cylinders were immersed in water for 90 Days curing is shown in figure. The specimen is drying in oven at temperature of $100+10 \mathrm{oC}$ were immerged with water level not more than $5 \mathrm{~mm}$ above the base of the specimen. The quantity of water penetrate into the specimen in time period of 30 minutes was measured by weighting the specimen on balance weighting. Sorptivity is computed using equation:

$$
\mathrm{S}=\mathrm{W} / \mathrm{A} \times \mathrm{t}^{1 / 2} \mathrm{~mm} / \mathrm{min}^{0.5}
$$

$\mathrm{W}=$ Weight difference

$\mathrm{A}=$ Surface area in $\mathrm{mm} 2$.

$\mathrm{t}=$ time elapsed in min.

For this test weight of specimen before and after water penetrations is given and also given the $\%$ water absorptions in the table.

Table 4: Test Results of Sorptivity test for different mixes.

\begin{tabular}{|c|c|c|c|c|}
\hline Mix & $\begin{array}{c}\text { Mix } \\
\text { no }\end{array}$ & $\begin{array}{c}\text { Wet wt. in } \\
\text { grams }\end{array}$ & $\begin{array}{c}\text { Dry wt. in } \\
\text { grams }\end{array}$ & $\begin{array}{c}\text { Sorptivity value in } \mathrm{mm} / \\
\min ^{0.5} \times 10^{-5}\end{array}$ \\
\hline $100 \%$ OPC & 1 & 1005.6 & 1003.7 & 4.41 \\
\hline $50 \%$ OPC+50\% GGBS & 2 & 992.8 & 990.3 & 5.81 \\
\hline $49 \%$ OPC+50\% GGBS+1\% NS & 3 & 976.6 & 975.3 & 3.02 \\
\hline $48 \%$ OPC+50\% GGBS+2\% NS & 4 & 1010.2 & 1009.1 & 2.56 \\
\hline $47 \%$ OPC+50\% GGBS+3\% NS & 5 & 997.2 & 996.4 & 1.86 \\
\hline $46 \%$ OPC+50\% GGBS+4\% NS & 6 & 956.4 & 955.9 & 1.16 \\
\hline $45 \%$ OPC+50\% GGBS+5\% NS & 7 & 992.3 & 991.6 & 1.63 \\
\hline
\end{tabular}

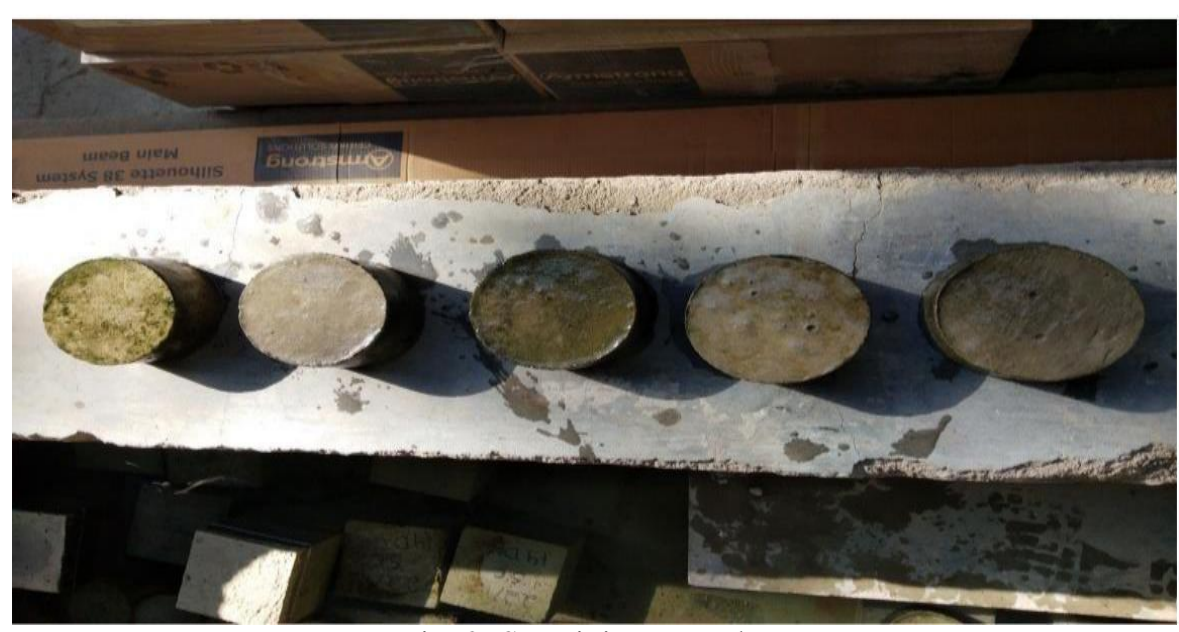

Fig. 2: Sorptivity test cubes.

\subsection{Sulfate Attack Test}

Environment containing many chemicals like sulfate and chloride ions etc. Due to this deterioration, expansion and cracking of concrete take place which can be identify in terms of loss in weight of the concrete. Sulfate attack is a test where sulfate ions attack the cement paste, due to this mechanical and durability properties of concrete are decreases. Evaluating the resistance of the sulfate attack we have considered weight loss as acceptable indicator and \% reduction in strength. For this test $50 \mathrm{~mm} \times 50 \mathrm{~mm} \times 50 \mathrm{~mm}$ size of cubes prepared and cured in 5\% Na2SO4 + 3\% MgSO4 solutions . Measurement are taking at end of 56, 90, 180 Days. In this Study Nano silica and mineral admixture GGBS are improved 
sulfate resistance attack in concrete. Study shows that the nano silca is significantly affect the sulfate resistance and replacement of $4 \%$ Nano silica of cement gives the best results.

Table 5: Test results of Sulfate attack test for different mixes.

\begin{tabular}{|c|c|c|c|c|}
\hline \multirow{2}{*}{ Mix } & Mix & \multicolumn{3}{|c|}{ Sulfate Resistance Expansion(\%) } \\
\cline { 3 - 5 } & no. & 56 Days & 90 Days & 180 Days \\
\hline $100 \%$ OPC & 1 & 0.105 & 0.124 & 0.152 \\
\hline $50 \%$ OPC+50\% GGBS & 2 & 0.07 & 0.082 & 0.091 \\
\hline $49 \%$ OPC+50\% GGBS+1\% NS & 3 & 0.043 & 0.055 & 0.062 \\
\hline $48 \%$ OPC+50\% GGBS+2\% NS & 4 & 0.036 & 0.049 & 0.056 \\
\hline $47 \%$ OPC+50\% GGBS+3\% NS & 5 & 0.025 & 0.039 & 0.047 \\
\hline $46 \%$ OPC+50\% GGBS+4\% NS & 6 & 0.012 & 0.026 & 0.037 \\
\hline $45 \%$ OPC+50\% GGBS+5\% NS & 7 & 0.031 & 0.041 & 0.046 \\
\hline
\end{tabular}

\subsection{Ultrasonic pulse velocity(UPV)}

Concrete are classified as excellent, good, poor and very poor using UPV value of $4500 \mathrm{~m} / \mathrm{s}$ and above, $3500-4500 \mathrm{~m} / \mathrm{s}$, $3000-3500 \mathrm{~m} / \mathrm{s}, 2000-3500 \mathrm{~m} / \mathrm{s}$ and $2000 \mathrm{~m} / \mathrm{s}$ or below. Standard procedures adopted as per IS 13311(Part-1). Transducers which is produce ultrasonic pulse is contact with one surface of concrete specimen and after traveling path length $(\mathrm{L})$ in the concrete, pulse of vibrations is converted into a electrical signal by second transducer held in contact with other surface of concrete specimen. Transit time(T) of the pulse is measured. The pulse velocity find using equation:

$$
\mathrm{V}=\mathrm{L} / \mathrm{T}
$$

For this test we were prepared a $150 \mathrm{~mm} \times 150 \mathrm{~mm} \times 150 \mathrm{~mm}$ cubes and cured at end of $28,56,90$ and 180 days. UPV values are given in the table for all mix combinations of 28 to 180 days. The maximum ultrasonic pulse velocity is recorded $5639 \mathrm{~m} / \mathrm{s}$ for Mix 6.

Table 6: Test results of ultrasonic pulse velocity test for different mixes.

\begin{tabular}{|c|c|c|c|c|c|}
\hline \multirow{2}{*}{ Mix } & Mix & \multicolumn{4}{|c|}{ Ultrasonic pulse velocity(UPV) $\mathrm{m} / \mathrm{s}$} \\
\cline { 3 - 6 } & no & 28 Days & 56 Days & 90 Days & 180 Days \\
\hline $100 \%$ OPC & 1 & 3896 & 4021 & 4559 & 5034 \\
\hline $50 \%$ OPC+50\% GGBS & 2 & 3916 & 4098 & 4630 & 5119 \\
\hline $49 \%$ OPC+50\% GGBS+1\% NS & 3 & 4032 & 4110 & 4792 & 5245 \\
\hline $48 \%$ OPC+50\% GGBS+2\% NS & 4 & 4121 & 4202 & 4808 & 5338 \\
\hline $47 \%$ OPC+50\% GGBS+3\% NS & 5 & 4190 & 4285 & 4902 & 5454 \\
\hline $46 \%$ OPC+50\% GGBS+4\% NS & 6 & 4225 & 4310 & 5067 & 5639 \\
\hline $45 \%$ OPC+50\% GGBS+5\% NS & 7 & 4087 & 4167 & 4934 & 5494 \\
\hline
\end{tabular}

\subsection{Acid Attack Test}

The concrete cube specimen of $100 \mathrm{~mm}$ x $100 \mathrm{~mm}$ x $100 \mathrm{~mm}$ of a various mixtures were cast and cure for 28 Days . After curing cube is allowed to dry for one days. For this test we found the $\%$ weight loss due to acid. The weight of sample are taken and after concrete cube specimen are immersed in the Hydrochloric acid(HCL) with pH about 2 at $5 \%$ weight of water. The cube specimen is immersed in the solutions for the period of Days and after 90 Days immersion cube is taken out and measure the weight of the sample. The resistance of concrete specimen to acid attack was found out by the $\%$ loss weight of specimen. For all the mix combination value are given in the graph. For this test Mix 6 the optimum result. 


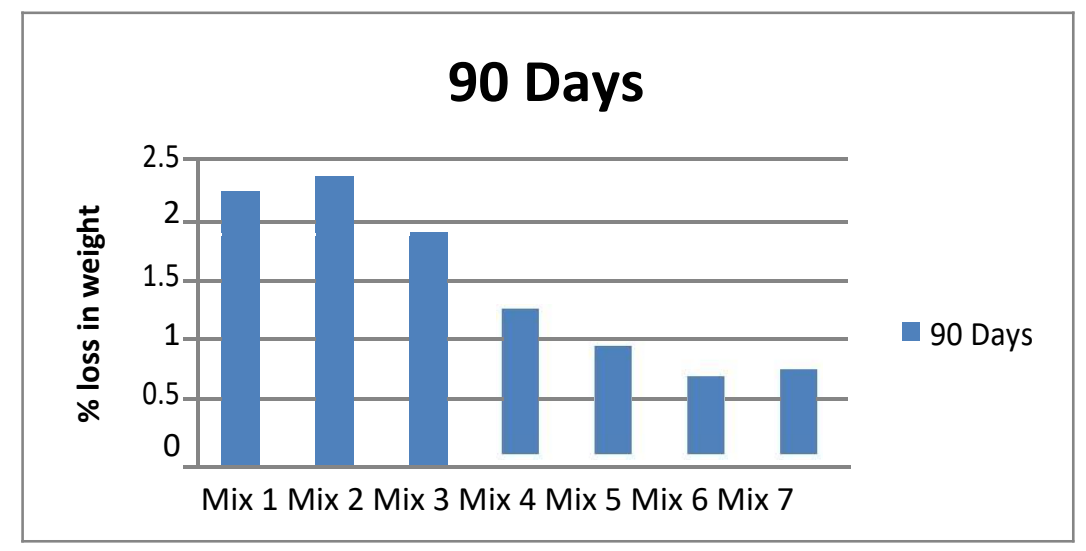

Figure 3: Acid attack test result of different concrete mixes.

\section{Conclusions}

This study show that experimentally evaluated of the combined effect of GGBS and Nano Silica on Durability properties of the High strength of concrete. The following conclusion can be drawn:

- In RCPT test we were found out that increases with Nano silica and SCMs charges passing through concrete cube is decreases. Ternary concrete Mix 6 and Mix 7 gives lower charge value compared with $100 \%$ controlled concrete.

- Sorptivity of the concrete with $4 \%$ replacement of nano silca with cement gives the low water penetrations compare to other mixes. Compare to Mix 1 and 2 all other mixes gives the low Sorptivity value.

- All ternary concretes shows the excellent durability to sulfate attack. After 180 days Plain concrete shows the maximum expansion $0.152 \%$ and Ternary mix (50\% GGBS, $46 \%$ OPC and $4 \%$ Nano Silica) shows the, minimum expansion $0.037 \%$.

- UPV test on all combinations have shown excellent results, which shows that utilization of the Nano silica and GGBS make concrete structure denser and increasing resistance to the moisture content. Maximum UPV value was found for Mix 6.

- Nano silica and GGBS combinations with cement (Ternary mix) showed excellent resistance to the acid attack. After 90 days minimum \% loss weight value found for Mix 6 and maximum \% loss weight value found for Mix 2.

- Ternary concrete could be the best substitute of OPC concretes. Utilization of the natural raw materials in construction may help in reducing the OPC and also utilize the waste materials in construction.

\section{References}

[1] A. M. Saida, M. S. Zeidana, M. T. Bassuonib, Y. Tiana, "Properties of concrete incorporating nano-silica" Construction and Building Materials (Elsevier).

[2] Niragi Dave, Anil Kumar Misra, Amit Srivastava, Anil Kumar Sharma, Surendra Kumar Kaushik "Study onquaternary concrete micro-structure, strength, durability considering the influence of multi-factors." Construction and Building Materials (Elsevier), vol. 139, pp. 447-457, 2017.

[3] Swapnil B., Walzade, V.R.Rathi, "Durability Study of High Strength Concrete Using Collidal Nano SiO2" International Journal of Innovative Research in Science, Engineering and Technology, vol. 5, no. 1, 2016.

[4] L. Ranjith Kumar, Q. Roger, P. Santhosh, K.Gowtham, E. D. Jothi Rajan "Durability Study Of Concrete Using Nano-Silica" International Journal of Advanced Research in Civil, Structural, Environmental and Infrastructure Engineering and Developing, vol. 2, no. 2, 2016.

[5] S. Senthil Selvan, "An Exprimental Study On The Effect of Nano Silica on Strength and Durablity of concrete" International Journal of Civil Engineering and Technology (IJCIET), vol. 8, no. 4, pp. 1182-1188, 2017.

[6] Jayeshkumar Pitroda, F. S. Umrigar "Evaluation of Sorptivity and Water Absorption of Concrete with Partial Replacement of Cement by Thermal Industry Waste (Fly Ash)," International Journal of Engineering and Innovative Technology (IJEIT), vol. 2, no. 7, 2013. 
[7] Ganesh, Ramachandra Murthy, Sundar Kumar, Mohammed Saffiq Reheman and Iyer "Effect of nanosilica on durability and mechanical properties of high-strength concrete" Magazine of Concrete Research, ICE Publishing.

[8] M Vijaya Sekhar Reddy, I. V. Ramana Reddy, K. Madan Mohan Reddy and C. M. Ravi Kumar, "Durability Aspects of Standard Concrete" International Journal of Structural and Civil engineering Research, vol. 2, no. 1, 2013.

[9] Kartika P., "An Experimental Study on Strength \& Durability of Concrete Using Partial Replacement of Cement with Nano Silica" International Journal of Scientific \& Engineering Research, vol. 7, no. 4, 2016. 